\title{
Atuação Docente na Educação Básica em Tempo de Pandemia
}

\author{
Flávia Marcele Cipriani' \\ Antônio Flávio Barbosa Moreira' \\ Ana Carolina Carius'
}

'Universidade Católica de Petrópolis (UCP), Petrópolis/RJ - Brasil

RESUMO - Atuação Docente na Educação Básica em Tempo de Pandemia. Este artigo considera a docência na Educação Básica, no contexto brasileiro, durante a pandemia da Covid-19 e suspensão das aulas presenciais. A pesquisa contou com a participação de 209 professores da cidade de Juiz de Fora, MG, que responderam ao questionário utilizado como instrumento. O objetivo foi analisar os pensamentos, sentimentos, desafios e perspectivas dos docentes nesse período de calamidade. Foi realizada a análise de conteúdo e a estatística descritiva dos dados. Os achados apontam conjuntos categoriais emergentes que destacam as preocupações docentes com as acentuadas desigualdades, as principais dificuldades nas práticas educativas curriculares e as expectativas dos profissionais da educação com o retorno às escolas.

Palavras-chave: Covid-19. Distanciamento Social. Educação Básica. Docência Remota. Práticas Educativas.

ABSTRACT - Teaching Performance on Educação Básica in Pandemic Time. This article considers teaching in Educação Básica, in the Brazilian context, during the Covid-19 pandemic and suspension of face-to-face classes. The survey was attended by 209 teachers from the city of Juiz de Fora, at Minas Gerais state, who answered the questionnaire used as an instrument. The objective was to analyze the thoughts, feelings, challenges, and perspectives of teachers in this period of calamity. Content analysis and descriptive statistics were performed. The findings point to emerging categorical sets that highlight the teachers' concerns with the marked inequalities, the main difficulties in curricular educational practices and the expectations of education professionals with the return to schools.

Keywords: Covid-19. Social Distancing. Basic Education. Remote Teaching. Educational Practices.

Educação \& Realidade, Porto Alegre, v. 46, n. 2, e105199, 2021. 
Atuação Docente na Educação Básica em Tempo de Pandemia

\section{Introdução}

Desde o final de 2019, o novo agente do coronavírus propaga-se rapidamente pelo mundo, afetando diversos segmentos da sociedade, entre esses o sistema de educação escolar. Segundo a Organização Mundial da Saúde (OMS), a Covid-19 é uma doença cujo quadro clínico pode variar de infecções assintomáticas a quadros respiratórios graves (OMS, 2020). Nesse sentido, mediante os crescentes índices de novos casos e óbitos em diversos países, em março de 2020, a doença foi caracterizada como uma pandemia e os países tiveram que envolver todo o governo e a sociedade com objetivo de salvar vidas e minimizar os impactos da calamidade (OMS, 2020).

No Brasil, as escolas de Educação Básica, devido à adoção da quarentena como medida para conter o contágio do vírus, tiveram as aulas presenciais suspensas. Saraiva, Traversini e Lockmann (2020) salientam que a paralisação das práticas nas escolas ocasionou a transposição das atividades escolares através do uso de ferramentas digitais, sobretudo nas instituições privadas de ensino. Para Dussel (2020), a sala de aula é um ambiente particular que habilita formas de trabalho com os saberes, que organiza corpos e os tempos em atividades, as quais propõem desafios intelectuais não alinhados aos arranjos educacionais improvisados na emergência. Nesse cenário, surge o desafio pela busca de alternativas para manutenção das atividades letivas. Dificuldades foram tensionadas nas comunidades escolares e cabe a menção a algumas normatizações dispostas para o enfrentamento do surto, sobretudo as que influenciaram o contexto educacional na cidade de Juiz de Fora, Minas Gerais.

A Lei no. 13.979, de 06 de fevereiro de 2020 (Brasil, 2020a), que dispõe das possíveis medidas voltadas à proteção da coletividade, estabelece que o distanciamento social e a quarentena são alternativas para evitar a propagação do novo coronavírus. Em vista do disposto, o Decreto $n^{\circ}$. 47.886, de 15 de março de 2020 (Minas Gerais, 2020b) instituiu o Comitê do Plano de Prevenção e Contingenciamento em Saúde da Covid-19, conforme situação de emergência de Saúde Pública declarada pelo Decreto NE no. 113, de 12 de março de 2020 (Minas Gerais, 2020a), para decisões sobre a implementação de medidas no estado, de acordo com a fase de contenção e mitigação da epidemia.

O crescente número de casos, no Brasil e em Minas Gerais, levou o Comitê Extraordinário Covid-19 a oficializar a deliberação nº. 18, de 22 de março de 2020, estabelecendo que as atividades presenciais na Educação Básica, no Sistema Estadual, deveriam ser suspensas por tempo indeterminado (Minas Gerais, 2020c). Ademais, o Conselho Estadual de Educação (Minas Gerais, 2020d) publicou, em 27 de março de 2020, orientações relacionadas à reorganização das atividades escolares, determinando que, no Ensino Fundamental e no Ensino Médio, em caráter excepcional, quaisquer componentes curriculares poderiam ser trabalhados remotamente, observadas as possibilidades de acesso on-line dos estudantes e professores. Sublinha-se que o documento não trouxe 
nenhuma previsão da modalidade não presencial para a Educação Infantil.

Em 28 de abril de 2020, o Conselho Nacional de Educação (CNE) aprovou as Diretrizes para orientar escolas da Educação Básica e Instituições de Ensino Superior durante a pandemia (Brasil, 2020b). Essas sugeriram que estados e munícipios buscassem alternativas para minimizar a necessidade de reposição presencial de dias letivos, a fim de manter um fluxo de atividades escolares aos estudantes, enquanto perdurasse a situação de emergência. Também, autorizaram os sistemas de ensino a computar atividades não presenciais para cumprimento de carga horária, elencando uma série de atividades não presenciais que poderiam ser utilizadas durante a situação pandêmica. Videoaulas, plataformas virtuais, redes sociais, programas de televisão ou rádio e material didático impresso foram algumas das possibilidades sugeridas. Na busca por soluções eficientes para evitar o aumento das desigualdades, da evasão e da repetência, o CNE recomendou que as atividades fossem ofertadas desde a Educação Infantil.

Nota-se que o sistema de educação escolar sofreu instabilidades e discrepâncias devido à imprevisibilidade provocada pela propagação mundial da Covid-19. Morgado, Sousa e Pacheco (2020) afirmam que a mudança na forma de trabalho dos professores é um bom exemplo, haja vista que o ensino on-line adotado acelera, de modo intenso, o predomínio da subjetividade digital. Ferreira e Barbosa (2020) ressaltam que a pandemia leva as instituições de ensino, públicas e privadas, a suscitarem o debate do papel da educação na sociedade atual. Nessa premissa, a presente pesquisa justifica-se pela necessidade de dar voz aos docentes da Educação Básica, envolvidos diretamente nas circunstâncias vivenciadas pelas instituições escolares, para que pensamentos, sentimentos, desafios e perspectivas possam ser reconhecidos e analisados, em benefício da educação e de todos os envolvidos no processo de ensino-aprendizagem.

\section{Método}

O presente estudo utilizou o questionário como técnica de coleta dos dados. Adotou-se a estatística descritiva e a análise qualitativa das respostas emergentes dos 209 professores da Educação Infantil ao Ensino Médio da Educação Básica, na cidade de Juiz de Fora, MG. Segundo Chaer, Diniz e Ribeiro (2011), o questionário é uma técnica bastante viável e pertinente quando se trata de problemas cujos objetos de pesquisa correspondem a questões de cunho empírico, envolvendo opiniões, percepções, posicionamentos e preferências dos pesquisados.

O questionário foi elaborado pelo Google Forms, com perguntas de múltipla escolha e discursivas. Segundo Gil (1999), as questões do instrumento devem ser formuladas de maneira clara, concreta e precisa, não sugerir respostas e abordar uma única ideia de cada vez, possibilitando uma interpretação mais assertiva. Chaer, Diniz e Ribeiro (2011) argu- 
mentam que o pesquisador deve formular questões em número suficiente, considerando o tema proposto e a ordem das indagações, para que haja conexão.

Em relação à estrutura do formulário, enviado para todos os participantes pelo WhatsApp ou por Messenger, essa apresentou, inicialmente, os pesquisadores e o tema do estudo. Em seguida, exibiu o Termo de Consentimento Livre e Esclarecido (TCLE) com o objetivo e a justificativa da pesquisa, bem como as garantias do anonimato dos participantes e da consolidação dos resultados. Para prosseguir com o questionário, os participantes deveriam clicar antes na opção de aceite. Marconi e Lakatos (1999) ressaltam a importância de ser enviada, junto com o questionário, a natureza da pesquisa, sua importância e a necessidade de obter respostas, buscando despertar o interesse do convidado em participar do estudo. Nas questões objetivas do formulário, os participantes assinalaram uma ou mais opções e escreveram sobre outras alternativas não constantes no instrumento. Nas questões discursivas, os participantes redigiram, livremente, um parágrafo para suas respectivas respostas. Chaer, Diniz e Ribeiro (2011) ponderam que as perguntas abertas permitem a liberdade de respostas, nas quais pode ser utilizada a linguagem própria do respondente.

Para a análise dos dados, adotou-se a técnica de Análise de Conteúdo proposta por Bardin (2011). Segundo a autora, o objeto, nessa análise, é a palavra, a prática da língua realizada por emissores identificáveis na busca de realidades através das mensagens. A técnica visa ao conhecimento de variáveis de ordem psicológica, sociológica, histórica, entre outras, por meio de um mecanismo de dedução, com base em indicadores reconstituídos a partir de uma amostra de mensagens particulares.

Consideraram-se as diferentes fases da Análise de Conteúdo, que se organizam em: a) pré-análise, fase da organização para tornar operacionais e sistematizar as ideias iniciais no esquema do desenvolvimento das operações sucessivas do plano de análise; b) exploração do material, uma fase longa e fastidiosa, que consiste em operações de codificação, desconto ou enumeração, em função de regras previamente formuladas; e c) tratamento dos resultados, inferência e interpretação - nessa fase, os resultados brutos são tratados de maneira a serem significativos e válidos (Bardin, 2011).

\section{Resultados e Discussão}

Os resultados das questões de formato fechado foram organizados em quadros com gráficos que analisam o perfil dos participantes e as tecnologias utilizadas na prática da docência remota, durante a pandemia da Covid-19. 
Quadro 1 - Perfil dos Participantes

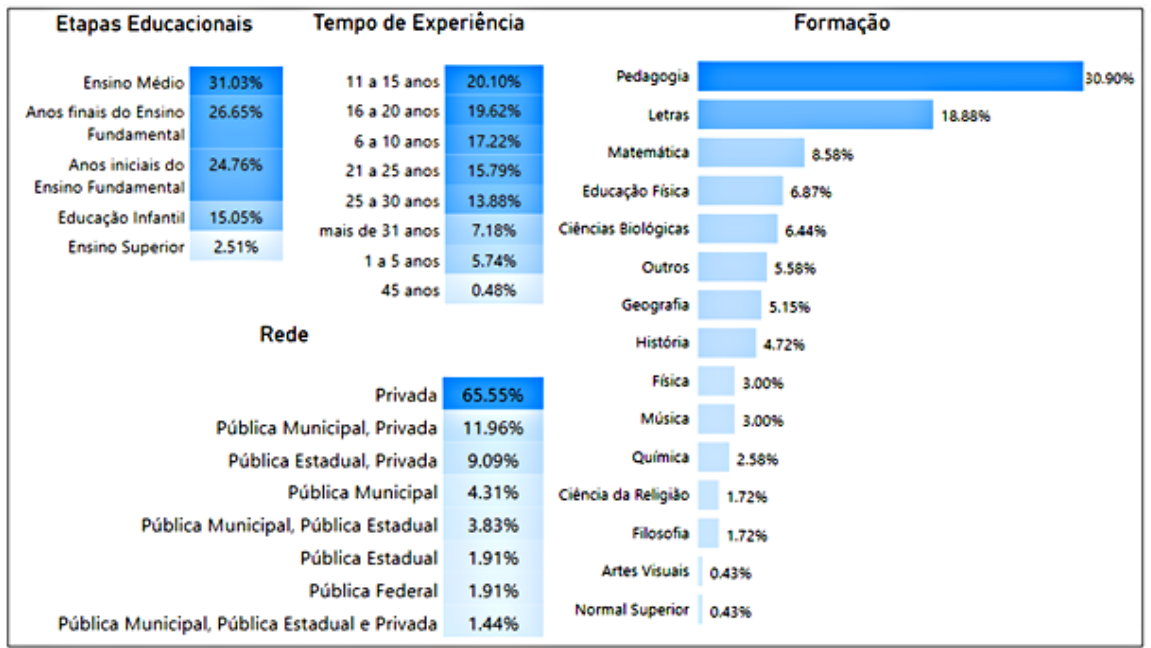

Fonte: Cipriani, Moreira e Carius (2020).

O Quadro 1 evidencia que a maioria dos professores participantes atua no Ensino Médio (31,03\%). Respectivamente, a concentração da amostra indica que os professores lecionam nos anos finais do Ensino Fundamental (26,65\%), nos anos iniciais do Ensino Fundamental (24,76\%), na Educação Infantil (15,05\%) e no Ensino Superior $(2,51 \%)$. Esta última etapa, apesar de não fazer parte da presente pesquisa, emergiu devido ao fato de professores que lecionam no Ensino Médio atuarem também no Ensino Superior. Nessa premissa, acrescenta-se que os dados revelaram que 55,98\% desses profissionais lecionam, exclusivamente, em uma etapa de ensino da Educação Básica, que 36,37\% trabalham em duas e que $7,65 \%$ atuam em três ou quatro etapas educacionais, como os professores licenciados em Música, Filosofia, Letras ou Educação Física.

Em relação ao tempo de experiência, nota-se que o maior percentual $(20,10 \%)$ se concentra no período de 11 a 15 anos de docência. Em seguida, entre 16 e 20 anos (19,62\%), entre 6 e 10 anos (17,22\%), entre 21 e 25 anos (15,79\%), entre 25 e 30 anos (13,88\%) e há mais de 31 anos $(7,18 \%)$. Cabe ressaltar que um dos participantes afirmou atuar como docente há 45 anos $(0,48 \%)$. Vale lembrar que esta pesquisa contou com a contribuição de profissionais com diferentes tempos de atuação, o que corrobora a heterogeneidade da amostra deste estudo.

Observa-se que, ao enfocar a formação dos participantes, os dados apontam um maior agrupamento de professores licenciados no curso de Pedagogia (30,90\%). Acredita-se que seja pelo fato de esse curso ser voltado aos professores que atuam, principalmente, nas duas primeiras etapas da Educação Básica: Educação Infantil e anos iniciais do Ensino Fundamental. Em seguida, evidencia-se a formação no curso de Letras (18,88\%), o que é justificável, pois, além de a Língua Portuguesa 
ser, geralmente, uma disciplina com maior número de aulas na matriz curricular, esse é um curso que também licencia professores de Literatura e outras línguas, como Inglês e Espanhol. Nota-se, contudo, que, nas principais licenciaturas, houve representatividade de professores, embora os percentuais sejam distintos. Ademais, salienta-se que o percentual de $5,58 \%$ foi enquadrado na barra denominada Outros pelo fato de os participantes terem feito, além da licenciatura, outros cursos de bacharelado como Direito, Psicologia, Engenharia Elétrica, Comunicação e Serviço Social.

No que se refere à rede de atuação, a maior concentração dos professores participantes localiza-se na rede privada de ensino $(65,55 \%)$ Percebe-se que parte dos participantes atua tanto na rede privada quanto na rede pública, em esfera municipal $(11,96 \%)$, estadual $(9,09 \%)$ ou, ainda, na rede privada e na rede pública municipal e estadual $(1,44 \%)$. $\mathrm{N}$

\section{Quadro 2 - Adesão à Docência Remota e Adoção de Plataformas e Tecnologias}

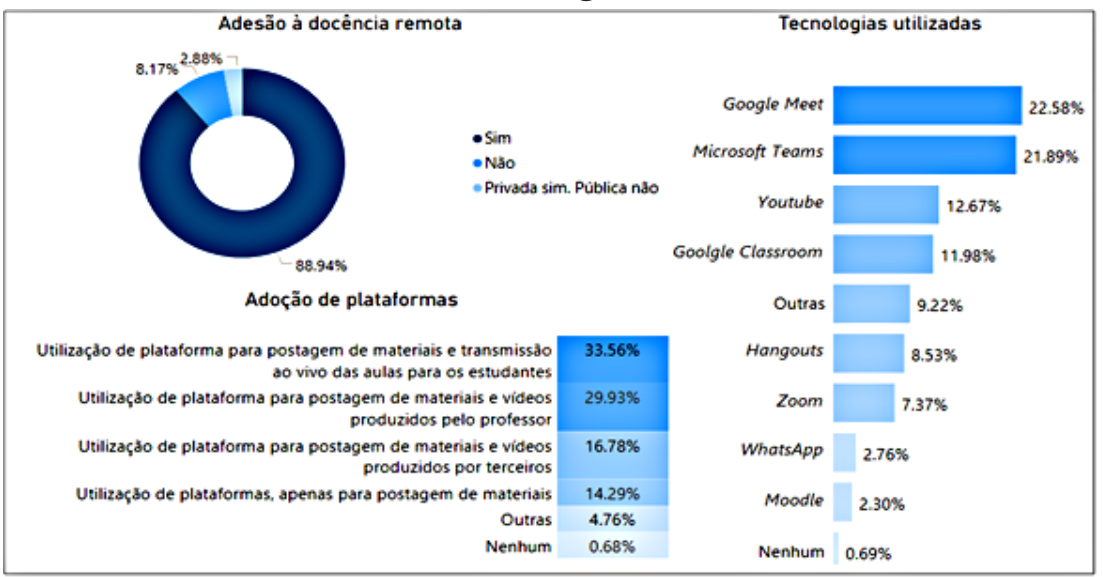

Fonte: Cipriani, Moreira e Carius (2020).

O Quadro 2 ilustra a organização dos dados referentes à adesão à docência remota e à adoção de plataformas e tecnologias no sistema educacional de Juiz de Fora, mediante a pandemia. Considera-se que $88,95 \%$ dos participantes estavam, de alguma forma, lecionando por meios digitais, o que representa a grande maioria da amostra deste estudo. Os resultados apontam que $8,17 \%$ dos professores afirmaram que não estavam atuando na Educação de forma remota e que 2,88\% informaram estar lecionando remotamente na rede privada, enquanto a rede pública na qual trabalham ainda não havia adotado esse sistema. Sublinha-se que o período de coleta dos dados desta pesquisa ocorreu entre os meses de abril e maio de 2020 e que, até o momento, a rede pública de ensino não havia efetivado nenhuma prática educacional, após a suspensão das aulas presenciais. 
As tecnologias mais utilizadas pelos professores, no contexto educacional remoto, associam-se ao Google Meet $(22,58 \%)$ e ao Microsoft Teams (21,89\%). Cabe mencionar que, em menor percentual, aparecem o YouTube (12,67\%), o Google Classroom (11,98\%), o Hangouts (8,53\%), o Zoom (7,37\%), o WhatsApp (2,76\%) e o Moodle (2,30\%). Percebeu-se que as palavras Outras $(9,22 \%)$ e Nenhum $(0,69 \%)$ também foram enunciadas pelos participantes, ao se referirem à adoção de novas tecnologias digitais em suas práticas docentes.

No que tange à adoção de plataformas, os maiores percentuais concentram-se na utilização dessas para postagem de materiais e transmissão de aulas ao vivo aos estudantes (33,56\%), seguidos da utilização da plataforma para postagem de materiais e vídeos produzidos pelo professor (29,93\%). Entretanto, o uso de plataformas para postagens de materiais e vídeos produzidos por terceiros (16,78\%), ou apenas para a postagem de materiais (14,29\%), apareceram nos resultados. Notou-se, também, que a opção Outras $(4,76 \%)$ esteve presente nas respostas, sendo que a opção Nenhum $(0,68 \%)$ também foi apontada, mostrando a ausência de uso de algum tipo de plataforma pelas instituições escolares.

Os resultados das questões discursivas foram organizados a partir da Análise de Conteúdo. Bardin (2011) assevera que a codificação se efetiva a partir de regras precisas ao considerar os dados brutos do texto, que, por recorte, agregação e enumeração, permitem atingir uma representação do conteúdo. Nessa perspectiva, considerou-se a organização mediante a escolha das unidades, a enumeração na contagem das palavras, a classificação e a agregação na definição das categorias.

As informações emergentes dos questionários respondidos foram agrupadas em conjuntos categoriais, conforme apresentados no infográfico (Figura 1).

\section{Figura 1 - Conjuntos Categoriais do Estudo}

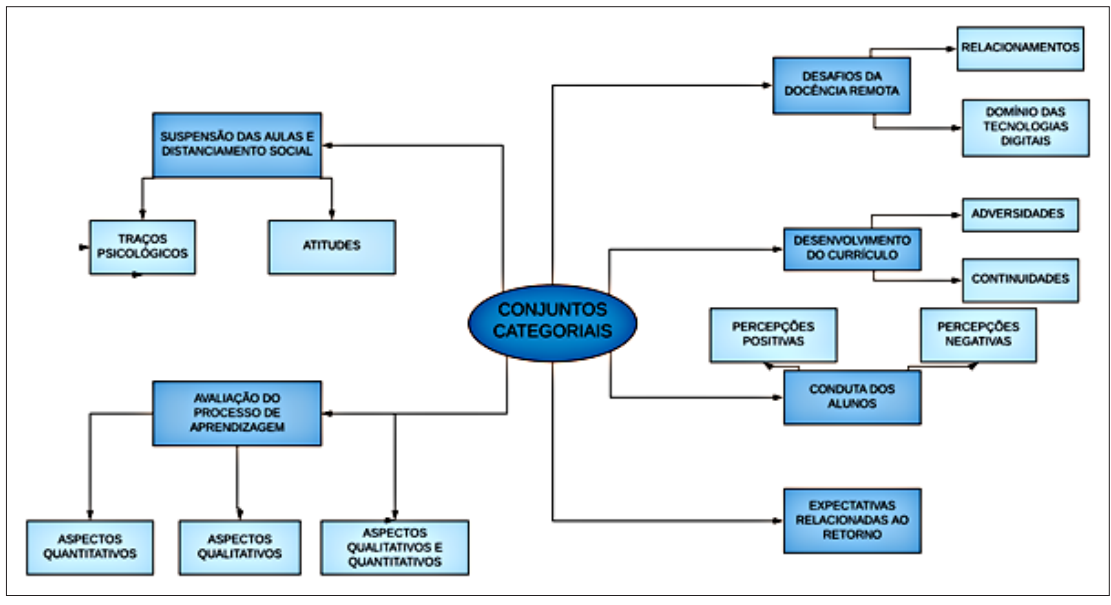

Fonte: Cipriani, Moreira e Carius (2020). 
Os conjuntos categoriais emergidos da definição inicial das categorias analíticas, pelo agrupamento de sentido dos elementos de conteúdo, foram: Suspensão das Aulas e Distanciamento Social; Desafios da Docência Remota, Desenvolvimento do Currículo, Avaliação do Processo de Ensino-Aprendizagem; Conduta dos Alunos e Expectativas Relacionadas ao Retorno das Aulas Presenciais. Ademais, na categorização final, ao ser estimado maior critério e profundidade dos recortes de conteúdo, foi realizada a consolidação de categorias que se atrelam às iniciais, conforme representado na Figura 1.

Algumas unidades de contexto foram selecionadas para ilustrar a discussão dos resultados em cada uma das categorias. No entanto, devido ao elevado número de participantes, são apresentados apenas alguns exemplos de sintagmas que emergiram das explanações e que corroboraram, dentre tantas outras, com a saturação dos resultados. Realça-se que foram atribuídos códigos para cada resposta, organizados de acordo com o perfil de cada respondente, preservando a identidade dos docentes. Dessa forma, além de receberem um número, foram especificadas as etapas nas quais os profissionais atuam: Educação Infantil (EI), Anos Iniciais do Ensino Fundamental (AIEF), Anos Finais do Ensino Fundamental (AFEF), Ensino Médio (EM), e, também, a Rede: Pública (Pub) e/ou Privada (Pri). Em caso de atuação do professor em mais de uma etapa educacional ou rede de ensino, as abreviações foram somadas em um único código e separadas por hífen, conforme o exemplo: (EI-AIEFPub11).

\section{Suspensão das Aulas Presenciais e Distanciamento Social}

Observou-se que a suspensão das aulas presenciais e o distanciamento social desencadearam nos professores uma série de pensamentos, sentimentos e atitudes que merecem destaque. Nessa abordagem, para melhor organização desse conjunto categorial, duas categorias foram estruturadas: a) traços psicológicos e b) atitudes.

\section{Traços Psicológicos}

O estado de ansiedade, a preocupação e a angústia foram palavras bastante repetidas pela maioria dos participantes, bem como a saudade que sentem do contato presencial com os alunos. Ademais, termos que revelam medo, insegurança, susto, cautela, desconforto, incerteza, confusão, reflexão e impotência também foram mencionados pelos docentes. Chamam a atenção afirmações de que os docentes se sentem incomodados, que estão cansados, esgotados, exaustos, estressados, pressionados, sobrecarregados, tensos, deprimidos, irritados, sentindo-se mal, frustrados, entediados e tristes, o que aponta para a possibilidade de que o psicológico e a saúde emocional dos profissionais tenham sido afetados pela situação vivenciada, portanto, merecem atenção e cuidados. Faragher, Cass e Cooper (2005) afirmam haver in- 
tensa associação entre baixos níveis de satisfação com o trabalho e problemas mentais e psicológicos, tais como Burnout, baixa autoestima, depressão e ansiedade. As expressões, a seguir, representam algumas das respostas dos professores:

\begin{abstract}
A ansiedade e preocupação tomam conta de toda preparação para as aulas, nem todos os conteúdos conseguimos trabalhar on-line, o que gera também frustração (EIPri5). Estou tensa e ansiosa! Tudo é novo! O isolamento, a forma de trabalhar, conviver com o perigo iminente! (AFEFPri15). Meu sentimento é de saudade dos alunos, da sala de aula e da convivência escolar. E, também de preocupação e medo diante da situação vivenciada pelo país (EIPri51). Me sinto exausta e tentando manter uma rotina menos estressante possível (AIEFPri61). Sinto-me angustiado diariamente [...] (EMPri71). Emocionalmente cansada e profissionalmente esgotada (AIEFPri131). Com muito medo, inseguranças e muito trabalho (AIEFPri150). É uma situação estressante e muito cansativa [...] (AIEFPub153). A sensação é de insegurança e de preocupação diante da situação e de seus possíveis desdobramentos. Juntamente, há uma sobrecarga física e mental [...] (AFEFEMPri182). Eu estou com muito medo de tudo que vem ocorrendo. A pandemia trouxe medos, desafios e incertezas. Tenho um medo compulsivo de retorno ao trabalho, por pessoas e limpeza [...] (AIEFPub195).
\end{abstract}

Mediante o exposto pela grande maioria dos participantes, em todas as etapas educacionais deste estudo, observa-se que os resultados apresentam pensamentos e sentimentos que geram desconfortos. Ao considerar questões atuais na formação e atuação docente, Moreira (2001) defende a articulação entre interioridade e exterioridade, ou, em outros termos, entre a relação do docente com o seu próprio eu e a sua relação externa com o mundo. Saraiva, Traversini e Lockmann (2020, p. 2) enfatizam que a Covid-19 "[...] irrompe de forma abrupta para nos lembrar da fragilidade humana”, o que desencadeia medos como o do desemprego, da fome, da violência, de um devir que se abre sem garantia, da certeza de que não voltaremos a ser o que éramos. Dussel (2020) esclarece que o clima afetivo particular se associa à surpresa, à ansiedade e mistura variáveis de pessimismo e otimismo.

\title{
Atitudes
}

Percebeu-se que os docentes, apesar das dificuldades, estavam se adaptando à situação do distanciamento social. O estudo revelou novas aprendizagens com a suspensão das aulas presenciais e com a adoção de diferentes meios e recursos de trabalho para as aulas on-line. Nessa direção, as distintas ferramentas e metodologias emergiram como desafios e descobertas. A necessidade de se reinventar, de ressignificar práticas e o incentivo à criatividade foram reforçados no cotidiano educacional, em tempos de pandemia. Nesse contexto, os professores afirmaram que as demandas aumentaram e que estão trabalhando 
muito mais do que o habitual, o que ocasionou a sobrecarga pelo maior esforço e dedicação. Gasparini, Barreto e Assunção (2005) mencionam a validade de estudos voltados para compreender a inadequação entre as mudanças educacionais propostas e implementadas, bem como a realidade que os trabalhadores enfrentam. As contradições existentes podem estar na origem da exposição aos fatores de risco para o adoecimento da categoria dos profissionais da educação. A seguir, exemplos de frases selecionadas pelo recorte das mensagens:

É bastante complicado, pois da noite para o dia me transformei em um professor YouTube. Por outro lado, estou aprendendo novas formas de ensinar, pois gosto de desafios (EMPri32). É uma situação nova, na qual são feitos muitos erros e acertos. Mas num panorama geral tem sido um tempo de descoberta de ferramentas e metodologias, assim como aplicar atividades que não teriam tanto sucesso em aula presencial (AFEFEMPri45). Confesso que estamos em tempos difíceis, houve muitas cobranças inicialmente. Tive que me adaptar e usar ferramentas que não tinha costume. Penso no lado positivo, fui 'forçada' a aprender muitas coisas (EI-AIEFPri-Pub47). É uma situação totalmente inovadora! Tive que aprender e me adaptar a essa, se podemos assim dizer, Nova Era da Educação Mundial (EMPri66).

Atitudes que se relacionam às crenças foram também notadas no conteúdo dos dados e merecem destaque. Termos como esperança, fé, perseverança, gratidão e pensamento positivo são exemplos de maior recorrência. Segundo Pátaro (2007), é possível afirmar que o sujeito possui determinadas crenças e tende a agir de acordo com elas, passando a pensar e a enxergar o mundo por meio delas. Seguem alguns pronunciamentos:

Com esperança, pois esse período de isolamento vai passar (AFEFPri154). Tenho buscado manter a tranquilidade através da fé (EMPub147). Colocando sempre Deus na frente de tudo para nos ajudar a vencer essa pandemia (AIEFPub-Pri152). Em todos os dias, tenho buscado leituras e orações para acalmar meu interior. Tenho mantido a esperança e a fé. Um sentimento também de gratidão pela vida (AIEF-AFEF-EMPri77).

Os resultados dos estudos de Melo et al. (2015) mostraram que a religiosidade e a espiritualidade se correlacionam à qualidade de vida $\mathrm{e}$ ao enfrentamento em situações adversas.

Nesse panorama de incertezas, acentua-se a importância do suporte voltado ao bem-estar psicológico dos professores. Saraiva, Traversini e Lockmann (2020) afirmam que a insegurança, a necessidade de adaptações rápidas, a invasão da casa pelo trabalho, a ansiedade frente às condições sanitárias e econômicas no cenário pandêmico estão causando nos professores um estado de exaustão.

\section{Desafios na Docência Remota}

Destacaram-se as afirmações dos professores associadas ao comprometimento das relações entre os envolvidos no processo educacional: professores, alunos e famílias. Nessa vertente, a ênfase nas tec- 
nologias da comunicação e informação na educação de forma remota desencadeou importantes provocações, articuladas às categorias: a) relacionamentos e b) domínios das tecnologias digitais.

\section{Relacionamentos}

Dificuldades para mobilizar, alcançar a atenção e a motivação na coordenação da participação de todos os alunos nas aulas on-line apareceram, recorrentemente, na análise dos resultados. Em seguida, também surgiram depoimentos que mostram a falta de compreensão e reconhecimento dos professores por parte das famílias, bem como o despreparo das mesmas no suporte aos alunos. Pondera-se, ainda, que a restrição do contato visual, do feedback dos alunos para os professores e dos professores para os alunos foram relatados como adversidades no contexto da sala de aula virtual. Brait et al. (2010) afirmam que a relação professor-aluno abrange todas as dimensões do processo ensino-aprendizagem que se desenvolve em sala de aula. Nesse âmago, percebeu-se, pelos sintagmas analisados, desafios e prejuízos causados pelo distanciamento físico, inclusive, na relação com as famílias dos estudantes:

É difícil alcançar todos os alunos, motivá-los e manter um bom ritmo de conteúdo (EMPri02). A aceitação dos pais, na verdade, o preconceito. Há relatos de que estamos só cumprindo contrato ou que o que é proposto é muito ruim... E aí, ao contrário, estamos nos desdobrando para que as crianças tenham um conteúdo de qualidade (EIPri05). Ausência de conexão visual sobre o acompanhamento dos alunos (EMPri06). Não ter o feedback dos alunos, como nas aulas presenciais (EMPub70). O grande desafio é proporcionar aos alunos uma atividade interativa, prazerosa e que prenda atenção (EIPri55). Gosto de ver os olhinhos brilharem ou até mesmo demonstrarem desinteresse! Gosto de tecnologia, mas amo pessoas! Não olhar no olho do meu aluno, para mim, é um desafio (AIEFAFEF-EMPri77). Não traz uma percepção total da mensagem que enviei a eles. Isso me aborrece (EMPri87). Gosto muito de observar as reações dos meus alunos durante as aulas, o que a aula on-line inviabiliza (AFEFPubPri86).

Torna-se evidente que a relação professor-aluno foi impactada com a mudança do formato das aulas presenciais para as aulas remotas. Brait et al. (2010) assinalam que a relação professor/aluno, em meio ao processo de ensino-aprendizagem, depende, fundamentalmente, do ambiente, da relação empática do professor com os alunos, da capacidade de ouvir, refletir e discutir o nível de compreensão dos estudantes. Destaca-se que, por mais que haja a possibilidade de interação pelos meios tecnológicos digitais, essa parece não ser satisfatória na Educação Básica, pelo fato de restringir o olhar atento do professor e limitar práticas que fortaleçam a participação e a compreensão dos sujeitos envolvidos. Ferreira e Barbosa (2020) ponderam que, em meio ao caos, professores e alunos que conseguem trabalhar remotamente esperançam o encontro, o abraço, os olhares. 
Atuação Docente na Educação Básica em Tempo de Pandemia

\section{Domínio das Tecnologias Digitais}

Aprender a lidar, a se adaptar à dinâmica das aulas on-line foi reiterado pelos participantes como uma situação desafiante, assim como a escassez de tempo para treinamentos, formações e orientações na preparação dos materiais e/ou aulas remotas. Em especial, a falta de equipamentos, de um ambiente adequado para as aulas, a produção de vídeos e a exposição da imagem pessoal emergiram como apontamentos relacionados como dificultosos pelos docentes, o que parece ter corroborado a insegurança relatada por alguns participantes. A instabilidade das conexões e a consequente dificuldade de acesso remoto foram também mencionados:

Primeiramente, ter uma Internet boa e, em seguida, trabalhar os conteúdos de forma atrativa aos alunos (EI-AIEFPub67). A dificuldade de gravar vídeos (EIPri162). Usar as ferramentas de vídeo (EIPri59). Espaço adequado com luz, silêncio e tranquilidade e estabilidade da Internet (AFEFEMPri145). Barulhos em casa como TV ligada, pais conversando, telefone tocando, alunos com dificuldade de acesso (AFEF-EMPub-Pri03). Ainda é difícil encontrar intimidade com a prática das videoaulas (AFEF-EMPub-Pri19). Adaptar e aprender em tempo hábil as ferramentas e suas funções. A exposição da minha imagem (EIPri20). Compreender o mecanismo de cada plataforma, pois possuem particularidades que tornam o trabalho cansativo (EMPri38). Entrar em contato com novas ferramentas e aprender rapidamente diante da necessidade (EMPub-Pri50). Aprender em tempo recorde o uso de diferentes plataformas (EMPri63).

Gadotti (2000), ao discutir sobre as perspectivas atuais da educação, afirma que a escola está desafiada a mudar a lógica da construção de conhecimentos e que, nessa direção, os jovens tendem a adaptar-se com mais facilidade do que os adultos ao uso do computador, por já nascerem nessa nova cultura, a digital. $\mathrm{O}$ autor realça, ainda, que as novas tecnologias criaram espaços de conhecimento e que a escola precisa ser um centro de inovação. Por outro lado, destaca que não se pode imaginar um futuro para a humanidade sem professores. Sublinha-se, nesse sentido, a importância da formação dos profissionais da educação para que as tecnologias digitais possam ser utilizadas como recursos efetivos, sem que as mediações docentes percam seu real valor na sociedade e nas interações presenciais com os alunos. Morgado, Sousa e Pacheco (2020, p. 5) reconhecem “[...] o contributo inestimável que as tecnologias têm propiciado, quer como suporte de vida, quer como esteio de relações", mas não descartam a "[...] possibilidade de todo este fenômeno resvalar para um futuro ainda mais dependente da tecnologia”.

\section{Avaliação do Processo de Aprendizagem}

As Diretrizes Nacionais para orientar as escolas em tempo de pandemia da Covid-19 (Brasil, 2020b) sugerem que as avaliações considerem as ações de reorganização dos calendários de cada sistema de ensino, antes que sejam estabelecidos os novos cronogramas das avaliações em larga escala. O documento ressalta, ainda, que é importante 
garantir uma avaliação equilibrada dos estudantes em função das diferentes situações que serão enfrentadas em cada sistema de ensino, assegurando as mesmas oportunidades a todos que participarem das avaliações em âmbitos municipal, estadual e nacional. As Diretrizes propõem que as avaliações e os exames de conclusão do ano letivo de 2020 das escolas levem em conta os conteúdos curriculares efetivamente oferecidos aos estudantes, considerando o contexto excepcional de calamidade pública, a fim de evitar o aumento da reprovação e do abandono no Ensino Fundamental e Médio.

Percebe-se, pelas orientações das Diretrizes, que o aspecto quantitativo parece preponderar o qualitativo, por mais que se mencione a atenção ao período de distanciamento social e o asseguramento das mesmas oportunidades da participação de todos os alunos nas avaliações. Cabe assinalar que, se dificuldades já eram notáveis para a garantia de oportunidades a todos os estudantes, considerando as desigualdades sociais constantes no Brasil, quanto mais desafiador parece ser em tempo pandêmico e de ensino remoto o acesso dos alunos em sua totalidade às tecnologias digitais e à Internet, que viabilizem a possibilidade e o direito à efetiva participação dos estudantes na realização das avaliações.

Enfatiza-se que, nos resultados da pesquisa, três aspectos avaliativos foram dimensionados como categorias: a) qualitativos; b) qualitativos e quantitativos; e c) quantitativos.

\section{Aspectos Qualitativos}

A observação do engajamento, da participação por áudio e/ou Chats, as dúvidas expressas pelos alunos nas aulas on-line e as respostas às perguntas feitas pelos professores durante essas aulas foram elencadas, repetidamente, como indicadores qualitativos no processo avaliativo. Acrescenta-se que também foi referido o retorno das atividades propostas aos alunos, tais como: os trabalhos, os vídeos gravados pelos estudantes, os exercícios e as questões do livro didático. Segundo Barreto (2001), a avaliação qualitativa valoriza o processo de aprendizagem e concentra-se nas possibilidades da criação de condições para que a escola trabalhe, diferentemente, com a diversidade dos alunos. Ressalta-se, ainda, que os professores afirmaram ser importante considerar, na condução do processo avaliativo, os sentimentos e as vivências dos alunos no contexto do distanciamento social e das aulas remotas:

Trabalhos e atividades que os alunos realizam em casa e encaminham por e-mail (EMPri04). A forma mais eficaz no momento, creio que seja a participação do aluno durante as aulas on-line, bem como a realizacão das atividades enviadas pela plataforma (EI-AIEFPub67). Através de fóruns e chats (AIEF-AFEF-EMPri77). Através da participação, da elaboração de perguntas e realização de atividades propostas (EMPri21). São momentos de conversa, de bate-papo e de troca de experiências. Estamos preocupados não somente com os conteúdos trabalhados, mas também com os sentimentos e as vivências das crianças nesse período (AIEFPri23). 
Atuação Docente na Educação Básica em Tempo de Pandemia

O feedback dos alunos e dos pais emergiu como um importante retorno ao processo qualitativo da avaliação. Um grupo de professores da Educação Infantil e anos iniciais do Ensino Fundamental alegou que não é possível avaliar os alunos dessa faixa etária à distância. Outro grupo de docentes, no entanto, informou que registros de fotos e vídeos feitos pelas crianças, com a ajuda dos pais, foram considerados na observação avaliativa:

Através de vídeo e fotos das atividades dos alunos, eles demonstram realmente se aprenderam e fizeram a atividade proposta. Eu posso comentar sobre os erros e acertos e o aluno corrige se necessário (AFEF-EMPubPri45). Ao final de cada dia, temos um feedback de cada responsável, por meio de mensagem, vídeo ou foto (EIPri111). Contamos com o apoio dos responsáveis neste processo, visto que os alunos são muito pequenos (AIEFPub-Pri157). Na Educação Infantil, o processo é feito por meio de registro de observação, visto que essa interação não é possível nesse contexto, não há avaliação de aprendizagem (EIPri170).

A Base Nacional Comum Curricular orienta, em relação à Educação Infantil, que o trabalho do educador compreende o conjunto de práticas e interações que garantam a pluralidade de situações e promovam o desenvolvimento pleno das crianças (Brasil, 2017). Percebese, por meio dos sintagmas escritos pelos professores participantes da pesquisa, que o processo avaliativo para a Educação Infantil fica ainda mais comprometido com a situação emergente vivenciada, pois, por mais esforços que os professores e as famílias façam à distância para atingirem o objetivo desejado, as mediações e experiências presenciais fazem toda a diferença no desenvolvimento integral das crianças.

\section{Aspectos Qualitativos e Quantitativos}

Notou-se, segundo as declarações dos professores, maior constância na avaliação dos alunos considerando tanto a abordagem qualitativa quanto a quantitativa, conforme os trechos a seguir:

Tenho pedido trabalhos a serem enviados por e-mail, faço atividade nas aulas on-line com eles, de registro ou oral, que pontuo. Também, estamos utilizando Google Forms para auxiliar nas avaliações bimestrais (EI-AIEFPri47). O processo tem se dado a partir da participação dos alunos por áudio e pelo Chat das plataformas em uma avaliação contínua. Também, conforme orientações das instituições escolares, têm sido empregadas avaliações por meio de atividades, provas e estudos dirigidos on-line (EMPril80). Perguntas orais, exercícios do material didático e avaliação pelo Forms. Feedback espontâneo durante as aulas e avaliações simuladas na plataforma Moodle. Tentamos avaliar todo o percurso, mas a instituição exigiu uma 'atividade avaliativa' formal feita no Google Forms (AFEF-EMPub-Pri169). Ao final de cada aula, proponho pequenas questões e já foi realizada uma avaliação bimestral através do Forms (EMPri142). Participação em aula, trabalho, atividades e prova através do Google Forms (AFEF-EMPri126).

Barretto (2001, p. 63) esclarece que “[...] a ênfase no processo e nas condições gerais em que são oferecidas o ensino torna-se essencial para que educadores, alunos e as próprias instituições educacionais usufru- 
am do potencial redirecionador da avaliação”. A situação pandêmica, nessa premissa, convida as instituições e os docentes, na pandemia e pós-pandemia, a refletirem sobre a avaliação e as condições para um efetivo domínio dos conhecimentos pelos estudantes, bem como para uma formação que se estenda a outras esferas.

\section{Aspectos Quantitativos}

Salientam-se, ainda, as declarações que as avaliações foram ou serão realizadas estritamente por meio de formulários digitais com questões objetivas, o que corrobora o aspecto avaliativo meramente quantitativo:

Avaliações objetivas postadas nas plataformas (EMPri38). Pela participação e testes rápidos pelo Forms (AFEF-EMPub-Priv39). Nesse período, fazem simulados on-line, montados por mim e aplicados pela plataforma da escola (EMPri87). Por meio dos formulários das plataformas (EMPri63). Através do Google Forms, montamos a avaliação e os alunos têm um prazo de 15 dias para responder (AIEFPri196).

A apreciação de resultados padronizados, de acordo com Barretto (2001), valoriza o produto da aprendizagem, utiliza, largamente, recursos quantitativos e alta tecnologia na avaliação do rendimento escolar. Assenta a autora, que a apreciação exclusiva de alguns aspectos cognitivos do currículo deixa de lado importantes dimensões na formação do educando. Ressalta-se que, mesmo com o cenário de calamidade nacional e mundial, a tradição de avaliar para quantificar parece ainda se fazer presente na cultura escolar.

Houve, também, um relevante grupo de professores que afirmou não ter iniciado o processo de avaliação com os alunos, conforme alguns exemplos a seguir:

Durante o período de aulas on-line, não haverá avaliações (EMPub209). Ainda não fizemos, especificamente, avaliações (AFEF-EMPub-Pril30). Até o presente momento, não estamos avaliando os alunos (EIPri55). Não há avaliações de nota ou de participação nesse período (AFEF-EMPubPri85).

Embora sejam reconhecidas as postulações qualitativas e quantitativas no processo de avaliação do ensino e da aprendizagem, as práticas apresentadas pelos professores apontam para a necessidade "[...] de retomar a função reguladora e a função emancipadora da avaliação a partir de nova ótica" (Barretto, 2001, p. 63). Saraiva, Traversini e Lockmann (2020, p.17) sublinham que as avaliações dos estudantes, via atividades remotas, devem ser feitas pelos docentes sem priorizar apenas as competências previstas em documentos oficiais, mas ampliando a visibilidade ao vivido e aprendido no momento de pandemia e isolamento social. Os autores ainda reforçam que a utilização de avaliações em larga escala, para verificar as aprendizagens dos alunos durante o período da educação remota, conecta-se à "[...] cultura de performatividade que cada vez mais impera nas searas educacionais." 
Atuação Docente na Educação Básica em Tempo de Pandemia

\section{Condutas dos Alunos}

A Base Nacional Comum Curricular (Brasil, 2017) enfatiza a formação pautada no desenvolvimento humano integral, que constitui indivíduos capazes de lidar com desafios individuais e coletivos, valorizando as crianças e os jovens em todas as suas dimensões: intelectual, física, emocional, social e cultural. O documento normativo salienta a importância de os alunos serem os protagonistas em sua aprendizagem e de participarem, ativamente, do processo de construção, consolidação e aplicação do conhecimento. Nessa direção, considerar as condutas dos alunos pela perspicácia dos docentes é um fator relevante a ser ponderado também na educação remota. A partir das exposições dos professores, foram consideradas duas importantes categorias de percepções: a) desfavoráveis e b) favoráveis.

\section{Percepções Desfavoráveis}

A grande maioria dos professores asseveraram notar os alunos desmotivados, apáticos e desinteressados. A falta de compromisso e/ou imaturidade foram citados de modo recorrente, assim como a menção à dificuldade de foco pelos estudantes, devido às distrações no ambiente doméstico. A pouca interação/participação durante as aulas por videoconferência e a ansiedade dos alunos também emergiram da análise de conteúdo:

Bastante ansiedade e pouca concentração (AFEF-EMPub-Pri03). Um pouco de apatia, desânimo e muita tensão (AFEFPril19). Alguns têm realmente se interessado, mas a maioria não está levando a sério (AFEFEMPub-Pri105). Poucos interagem, impressão de que muitos não estão participando (AFEF-EMPri30). Falta maturidade dos alunos para aderir a esse novo método (AIEFPri93). Insegurança e desinteresse diante das incertezas (AIEFPub-Pri18).

Torna-se evidente que o ambiente escolar favorece maior foco aos alunos e é mais propício para a organização e o desenvolvimento de hábitos de estudo. Segundo Moreira (2017), apesar de vivermos em momento de questionamentos ao projeto da modernidade e de mudanças nos contextos social, político, cultural e epistemológico, considerando os tempos pós-modernos, a escola ainda desempenha um relevante papel social, o que justifica a valorização das diversas subjetividades que coabitam em seu interior, na difusão do conhecimento escolar.

\section{Percepções Favoráveis}

Por outra vertente, alguns professores relataram também percepções positivas e afirmaram que os alunos estão participativos e comprometidos com as aulas remotas. Informaram que, surpreendentemente, os estudantes têm se adaptado bem ao ambiente virtual:

Grande aceitação do modelo ora oferecido (EIPri111). Têm se adaptado de forma muito satisfatória (AFEFPri43). A maioria dos alunos e famílias 
estão se envolvendo (AIEF-AFEF-EMPri35). Demonstram interesse e tentam participar da melhor forma possível (EIPri51). Estão muito participativos, conectados, em geral (EMPri32). Fiquei surpresa com o entusiasmo e a participação dos mesmos (EMPri92). Surpreendentemente, observei que alguns alunos apresentaram elevação nos níveis de proatividade (EIAIEFPub-Pri107).

Coelho (2012) reforça a importância de a escola, tanto em sua estrutura física quanto em relação às práticas docentes, adequar-se para receber o novo tipo de aluno, considerado nativo digital. Segundo a autora, esses estudantes, nascidos a partir dos anos 1980, são dotados de uma competência tecnológica natural, que deve ser explorada em sala de aula. Cabe, portanto, ao sistema de educação escolar se atentar para esse potencial dos alunos, de maneira a otimizar a aprendizagem nas instituições. Afinal, crises fundamentais curriculares do século anterior decorreram das inovações tecnológicas (Morgado; Sousa; Pacheco, 2020).

\section{Desenvolvimento do Currículo}

O currículo pode ser definido como “[...] uma construção e seleção de conhecimentos e práticas produzidas em contextos concretos e em dinâmicas sociais, políticas e culturais, intelectuais e pedagógicas" (Fernandes; Freitas, 2007, p. 9). Nesse panorama, ao refletir sobre escola, currículo e ensino, Moreira e Kramer (2007) ressaltam que vivemos em tempos hipermodernos, nos quais se assiste não à morte da modernidade, mas a sua conclusão.

Segundo Candau (2016), experiências insurgentes que apontam para outras formas de organização dos currículos, espaços, tempos, trabalho docente, relações com as famílias e comunidades, bem como relações de gestão e nas práticas, permanecem periféricas, não são visibilizadas de modo adequado, nem fortemente apoiadas. Morgado, Sousa e Pacheco (2020) focalizam que o currículo, como experiência centrada no indivíduo social, leva-nos a refletir sobre o papel dos decisores curriculares em tempo de confinamento social. Nessa direção, o contexto pandêmico vivenciado ressalta a necessária atenção ao currículo e seus desdobramentos. Acentua-se que duas principais categorias foram destacadas: a) adversidades e b) continuidades.

\section{Adversidades}

Os professores afirmaram que a situação emergente valida a necessidade de flexibilização e adaptações no processo educacional. Nessa perspectiva, a clareza e o foco em relação ao que é essencial se faz importante na reestruturação do currículo, o qual precisa ser repensado, refletido, considerando o presente e o futuro, segundo os participantes do estudo. Os docentes também salientaram que o tempo e o ritmo das aulas, bem como os conteúdos, tiveram de ser reduzidos, o que enseja o intricado questionamento de qual conhecimento é mais valioso na di- 
fusão do currículo (Pacheco, 2013), principalmente, em tempo de pandemia (Dussel, 2020). Para Macedo e Fragella (2016), o conhecimento que seria mais válido foi, por longo tempo, uma das questões centrais do campo do currículo e, se alguns ainda defendem essa centralidade, certamente, não o fazem com a mesma certeza de que há uma única resposta ou de que essa resposta paira acima de relações de poder.

Nessa perspectiva, segundo os relatos dos participantes desta pesquisa:

Tivemos que adaptar tudo, desde planejamento, atividades, avaliações, calendário escolar etc. (AIEFPri14). É preciso adaptar o currículo à nova realidade (AFEFPri15). A dinâmica de aprendizado é totalmente diferente. A necessidade do aluno não é o conteúdo. Isso ele tem na Internet. O que o aluno quer é refletir sobre o conteúdo existente. Assim, o professor tem que mudar a sua aula, fazendo o aluno se conectar com novos raciocínios (AIEF-AFEF-EMPri48). Acredito que a pandemia nos forçou a flexibilizar a ideia de uma educação tradicional conteudista e com o objetivo único de cumprir programas (AFEF-EMPub-Pri69). Obrigou a uma reelaboração completa do currículo (AFEF-EMPub-Pri39).

Percebe-se que a realidade vivenciada provocou importantes reflexões e possíveis ações relacionadas ao desenvolvimento do currículo. Segundo Pacheco (2013), a centralidade do currículo, na atividade educacional, justifica-se se esse for sinônimo de conhecimento, de referência a um corpus de saberes e valores, social e culturalmente reconhecido como válido. Morgado, Sousa e Pacheco $(2020$, p. 7) declaram que o confinamento provocado pela Covid-19 “[...] não pode criar um estado de isolamento do currículo, porque o currículo é, em essência, um espaço de partilha". Dessa forma, os autores realçam que será essencial uma nova conceptualização curricular, na qual o domínio dos estudos curriculares deverá focar-se.

\section{Continuidades}

Para um representativo número de professores, não houve grandes mudanças no currículo com a suspensão das aulas presenciais, apenas ocorreu a adequação dos meios. Também, expuseram que somente com o retorno ao contexto escolar presencial será possível uma melhor visão. Silva (2010) afirma que o uso de tecnologias nos processos de ensino e aprendizagem corrobora o movimento de integração ao currículo do repertório de práticas sociais de alunos e professores típicos da cultura digital vivenciada no cotidiano. Nessa premissa, Morgado, Sousa e Pacheco (2020) enfatizam a necessidade de um debate profundo acerca do papel do currículo e das tecnologias educativas para a sociedade. Seguem alguns depoimentos dos participantes desta pesquisa:

Acho que somente após a pandemia poderemos ter uma real avaliação sobre a influência desse processo no currículo (AFEF-EMPri126). Ainda não podemos mensurar o impacto causado (EMPri21). Não houve interferência no currículo, apenas readequações de planejamentos e atividades avaliativas (AFEF-EMPub-Pri82). Ainda não houve interferências 
no currículo, estamos seguindo com o que foi planejado para o ano de 2020 (EMPri142). Iremos pensar, coletivamente, sobre as interferências curriculares após o retorno às aulas (AIEFPub148). Não percebi interferência, infelizmente (AFEF-EMPub190). Só no fim vamos ter essa visão (AIEFPub-Pril1)

Alguns participantes nada declararam em relação ao currículo, o que pode ser reiterado pelo fato de parte da amostra atuar na rede pública de ensino, pois, até o momento da coleta dos dados, essa ainda não havia adotado o sistema de educação remota, agudizando acentuadas assimetrias sociais nas condições de acesso à educação. Moreira e Kramer (2007) ressaltam a tensão existente no processo curricular entre dois focos: o conhecimento escolar e a cultura, realçando que o currículo envolve tanto compreender o ambiente cotidiano como comprometer-se com sua transformação. Nessa direção, o cenário pandêmico reforça a importância da reflexão feita por Ponce (2009) ao questionar que mundo e que ser humano queremos ter daqui para frente. Os autores Morgado, Sousa e Pacheco (2020, p. 2) acrescentam: "Que transformações curriculares ocorrem perante a necessidade de confinamento social?"

\section{Expectativas Relacionadas ao Retorno às Aulas Presenciais}

Constatou-se a repetição de termos que se relacionam ao receio em relação à segurança e à dificuldade para administrar as questões sanitárias na prevenção do contágio da Covid-19, no retorno às aulas presenciais. A maioria dos professores esperam que esse retorno seja o quanto antes, embora seja difícil imaginar quando e como ocorrerá. Os profissionais têm a convicção de que será um momento marcado por inúmeros desafios e muitos afirmaram acreditar que não será em breve:

Muita saudade e expectativa para retornar o quanto antes, mas, acima de tudo, com segurança para todos. Muito receosa em saber como esse tempo impactou as crianças e familiares (EIPri20). Voltaremos reconhecendo o novo território que se instaurou com a chegada do vírus. Penso que, efetivamente, as aulas somente retornarão em agosto ou setembro. Acredito que será uma conjuntura bastante delicada (EMPri21). A possibilidade do contato físico, a discriminação daqueles que apresentarem algum sintoma da doença, a quantidade de alunos em sala. Enfim, será um momento de grandes desafios para nós, educadores (AFEF-EMPubPri37).

Estimaram os professores que haja maior valorização da convivência física, das relações humanas e do trabalho presencial do professor, por parte da comunidade escolar e sociedade como um todo, no retorno às aulas nas instituições de ensino:

Esse isolamento poderá ser responsável por uma valorização maior da presença física do professor, muitos pais estão percebendo os desafios que os professores enfrentam em uma sala de aula (AFEF-EMPub-Pri03). Tivemos que aprender a conviver longe das pessoas, tivemos que apren- 
Atuação Docente na Educação Básica em Tempo de Pandemia

der a olhar para o outro, mesmo que à distância, as nossas atitudes atingem, diretamente, o outro, e isso nunca ficou tão claro nesse momento (EI-AIEF-AFEF-EM13). A valorização do ser humano como ponto fundamental para a aprendizagem (AFEF-EMPub-Pri65). Acredito que não somos mais os mesmos, nem professores e nem alunos. Chegaremos a uma escola diferente, que vivenciou propostas diferentes. Seremos outras pessoas quando nos encontrarmos. Outras crianças, outros profissionais, outros pais (AIEFPril4).

Os participantes ressaltaram que algumas mudanças permanecerão e que estas se fazem necessárias à inovação na dinâmica da docência. Entretanto, afirmaram que será preciso um tempo para uma (re)adaptação, que estão apreensivos com os impactos emocionais, com a saúde mental dos alunos e professores pós-pandemia. Eles também se preocupam com o acolhimento na volta às aulas nas escolas. Nesse sentido, salientaram a importância da escuta e do diálogo, até mesmo porque acreditam que haverá uma grande diferença e defasagem entre os níveis de aprendizagem:

Precisaremos de um tempo de adaptação e, principalmente, de escuta dos alunos (EMPri04). Preocupada com o emocional e a saúde de todos, principalmente, nós, docentes, que estamos trabalhando sob telas quase 12 horas por dia (AIEFPri12). Penso que o normal, como conhecíamos, nunca mais existirá e, por isso, a tecnologia aplicada à aprendizagem será uma realidade efetiva nas instituições educacionais (EMPri41). Preocupado com o estado psicológico dos alunos (AFEFPri43). As crianças precisarão entender a rotina da escola novamente. Precisarão sentirem-se acolhidos e seguros novamente no ambiente escolar (EIPri51). Primeiro, não sabemos se esse retorno será normal, acredito que não. Acredito que mudaremos muito tanto no convívio social quanto na utilização de novas metodologias (EMPri63). Acho que está tudo muito perdido, não sabemos, exatamente, o que esperar, quando e como isso tudo vai acabar (EIPri72). Caso a sociedade não entenda que será necessário um período de adaptação para o retorno às aulas presenciais, isso será traumático! (AFEF-EMPub-Pri95).

Percebe-se que novos tempos, espaços e relações escolares tendem a ser desvendados na reorganização das aulas presenciais para que os sujeitos da comunidade escolar possam se (re)adaptarem de forma segura e efetiva. Dussel (2020) assevera que, diante da nova ordem ou desordem mundial, é importante manter o equilíbrio e sonhar com outra escola possível, outras formas de ensinar, outro elo com o conhecimento e a cultura nas relações escolares.

\section{Considerações Finais}

O presente artigo buscou reconhecer e analisar pensamentos, sentimentos, desafios e perspectivas vivenciados pelos professores da Educação Básica de Juiz de Fora durante a pandemia provocada pela Covid-19 e a consequente suspensão das aulas presenciais nas escolas de Educação Básica. As categorias emergidas neste estudo confluem com o questionamento de Dussel (2020) ao refletir sobre os efeitos da 
domestização das escolas em intersecção com as desigualdades préexistentes, com as tecnologias e práticas pedagógicas.

Os resultados da presente pesquisa apontaram que, enquanto as instituições da rede privada de ensino estavam, de alguma forma, oferecendo a educação remotamente, as escolas da rede pública ainda não haviam iniciado essa ação, o que acentua o cenário das desigualdades educacionais na cidade. Receios em relação à maneira como será desenvolvido o processo educacional nas escolas públicas foram configurados como problemática pelos professores participantes. Ferreira e Barbosa (2020) apontam que a situação precária para se praticar a docência remota e o acesso a essa emergente modalidade de ensino se somam às dificuldades dos alunos no ambiente doméstico, o que limita, ainda mais, o acesso à educação.

Os registros feitos pelos profissionais demonstraram estado de ansiedade, preocupação e angústia, culminados pela sobrecarga de trabalho na situação vivenciada, o que realça a importância do suporte voltado ao bem-estar psicológico dos docentes. As dificuldades na adoção de novos meios, recursos e metodologias pelos professores reforçam ser essencial a formação continuada e o maior suporte aos profissionais na aquisição e no uso das tecnologias da informação e comunicação, sem que as mediações docentes percam seu real valor na sociedade. Saraiva, Traversini e Lockmann (2020) enfatizam que a inclusão da tecnologia de forma tecnicista tende a colocar a atividade docente na Era do 24/7 (vinte e quatro horas e sete dias por semana), sem a separação entre o trabalho e a atividade doméstica. Essa premissa aponta a necessidade de se considerar as mudanças da profissão docente e seu significado na realidade digital (Morgado; Sousa; Pacheco, 2020) para evitar o sucateamento da carreira dos professores.

A limitação da interação entre professores e alunos foi considerada um fator preponderante, inclusive, pela ausência de importantes feedbacks no processo de ensino-aprendizagem. Nesse sentido, a presença física no contexto escolar foi considerada essencial na Educação Básica. Ademais, sublinha-se que as instituições escolares terão de avaliar os impactos causados no currículo e em seus desdobramentos. Morgado, Sousa e Pacheco (2020) salientam que é preciso encontrar sentidos sobre o fenômeno pandêmico vivenciado e analisar as consequências na construção curricular e no desenvolvimento pessoal e social dos indivíduos.

Acredita-se que, daqui para a frente, a educação escolar passará por muitas transformações e ressignificações. Nessa direção, estudos que considerem a Educação Básica em tempos de pandemia, em outras cidades e estados do país, parecem válidos para pensar a educação do futuro. 
Atuação Docente na Educação Básica em Tempo de Pandemia

\section{Referências}

BARDIN, Laurence. Análise de Conteúdo. São Paulo: Edições 70, 2011.

BARRETTO, Elba Siqueira de Sá. A Avaliação na Educação Básica entre Dois Modelos. Educação \& Sociedade, ano XXII, n. 75, ago. 2001.

BRAIT, Lílian et al. A Relação Professor/Aluno no Processo de Ensino e Aprendizagem. Itinerarius Reflectionis, Revista Eletrônica do Curso de Pedagogia do campus Jatái-UFG, v. 8, n. 1, jan./jul. 2010.

BRASIL. Base Nacional Comum Curricular. Brasília: MEC, 2017. Disponível em: <http://basenacionalcomum.mec.gov.br/images/BNCC_20dez_site.pdf>. Acesso em: 22 jun. 2020.

BRASIL. Lei no. 13.979, de 06 de fevereiro de 2020. Diário Oficial [da República Federativa do Brasil], Brasília, DF, Atos do Poder Legislativo, 2020a.

BRASIL. Diretrizes Para Orientar Escolas da Educação Básica e Instituições de Ensino Superior. Aprovada no dia 28 de abril de 2020, pelo Conselho Nacional de Educação (CNE). Brasília: Ministério da Educação, 2020b.

CANDAU, Vera Maria Ferrão. Cotidiano Escolar e Práticas Interculturais. Cadernos de Pesquisa, Maranhão, v. 46, n. 161, p. 802-820, jul./set. 2016.

CHAER, Galdino; DINIZ, Rosa Pereira; RIBEIRO, Elisa Antônia. A Técnica do Questionário na Pesquisa Educacional. Evidência, Araxá, v. 7, n. 7, p. 251-266, 2011.

COELHO, Patrícia Maria Farias. Os Nativos Digitais e as Novas Competências Tecnológicas. Texto Livre Linguagem e Tecnologia, Belo Horizonte v. 5, n. 2, 2012. Disponível em: <http://periodicos.letras.ufmg.br/index.php/textolivre>. Acesso em: 21 jun. 2020.

DUSSEL, Inês. A Escola na Pandemia: Reflexões Sobre o Escolar em Tempos Deslocados. Práxis Educativa, Ponta Grossa, v. 15, p. 1-16, jul. 2020.

FARAGHER, Brian; CASS, Monica; COOPER, Cary. The Relationship Between Job Satisfaction and Health: a meta-analysis. Occupational and Environmental Medicine, Londres, v. 62, p. 105-112, 2005.

FERNANDES, Cláudia de Oliveira; FREITAS, Luiz Carlos de. Indagações Sobre Currículo: currículo e avaliação. Organização do documento: Jeanete Beauchamp, Sandra Denise Pagel, Ariciléia Ribeiro do Nascimento. Brasília: MEC, Secretaria de Educação Básica, 2007. Disponível em: <http://portal.mec.gov.br/ seb/arquivos/pdf/Ensfund/indag5.pdf>. Acesso em: 15 maio 2020.

FERREIRA, Luciana Haddad; BARBOSA, Andreza. Lições de Quarentena: limites e possibilidades da atuação docente em época de isolamento social. Práxis Educativa, Ponta Grossa v. 15, p. 1-24, jul. 2020.

GADOTTI, Moacir. Perspectivas Atuais da Educação. São Paulo em Perspectiva, São Paulo, v. 14, n. 2, 2000.

GASPARINI, Sandra Maria; BARRETO, Sandhi Maria; ASSUNÇÃO, Ada Ávila. O Professor, as Condições de Trabalho e os Efeitos Sobre sua Saúde. Educação e Pesquisa, São Paulo, v. 31, n. 2, p. 189-199, maio/ago. 2005.

GIL, Antônio Carlos. Métodos e Técnicas de Pesquisa Social. 5. ed. São Paulo: Atlas, 1999.

MACEDO, Elizabeth; FRAGELLA, Rita de Cássia Prazeres. Apresentação - Políticas de currículo ou Base Nacional Comum: debates e tensões. Educação em Revista, Belo Horizonte, v. 32, n. 2, p. 13-17, abr./jun. 2016. 
MARCONI, Maria de Andrade; LAKATOS, Eva Maria. Técnicas de Pesquisa. 3. ed. São Paulo: Atlas, 1999.

MELO, Cyntia de Freitas et al. Correlação entre Religiosidade, Espiritualidade e Qualidade de Vida: uma revisão de literatura. Estudos e Pesquisas em Psicologia, Rio de Janeiro, v. 15, n. 2, p. 447-464, 2015.

MINAS GERAIS. Decreto NE nº. 113, de 12 de março de 2020. Diário do Executivo, Belo Horizonte, Caderno 1, 2020a.

MINAS GERAIS. Decreto no ${ }^{\circ}$ 47.886, de 15 de março de 2020. Publicado pelo governador do estado de Minas Gerais. Diário do Executivo, Belo Horizonte, Cadernol, 2020b.

MINAS GERAIS. Deliberação no. 18, de 22 de março de 2020. Belo Horizonte: Comitê Extraordinário COVID-19, 2020c.

MINAS GERAIS. Conselho Estadual de Educação, aos 27 dias de março de 2020. Orientações relacionadas à reorganização das atividades escolares. Belo Horizonte: Secretaria Estadual de Educação, 2020d.

MOREIRA, Antonio Flavio Barbosa; KRAMER, Sonia. Contemporaneidade, Educação e Tecnologia. Educação \& Sociedade, Campinas, v. 28, n. 100, p. 10371057, out. 2007. Edição Especial.

MOREIRA, Antonio Flávio Barbosa; SILVA JUNIOR, Paulo Melgaço da. Conhecimento Escolar nos Currículos das Escolas Públicas: reflexões e apostas. Currículo sem Fronteiras, v. 17, n. 3, p. 489-500, set./dez. 2017.

MOREIRA, Antonio Flávio Barbosa. Currículo, Cultura e Formação de Professores. Educar em Revista, Curitiba, n. 17, p. 39-52, 2001.

MORGADO, José Carlos; SOUSA, Joana; PACHECO, José Augusto. Transformações Educativas em Tempos de Pandemia: do confinamento social ao isolamento curricular. Práxis Educativa, Ponta Grossa, v. 15, p. 1-10, jul. 2020.

OMS. Organização Mundial da Saúde. Folha Informativa - COVID-19 (doença causada pelo novo coronavírus). Disponível em: <https://www.paho.org/bra/ index.php?option=com_content\&view=article \&id=6101: covid19\&Itemid=875> . Acesso em: 7 jun. 2020.

PACHECO, José Augusto. Estudos Curriculares: desafios teóricos e metodológicos. Ensaio: avaliação e políticas públicas em educação, Rio de Janeiro, v. 21, n. 80, p. 449-472, jul./set. 2013.

PÁTARO, Cristina Satiê de Oliveira. Pensamento, Crenças e Complexidade Humana. Ciências \& Cognição, Rio de Janeiro, v. 12, p. 134-149, dez. 2007.

PONCE, Branca Jurema. A Educação em Valores no Currículo Escolar. Revista E-Curriculum, São Paulo, v. 5, n. 1, dez. 2009.

SARAIVA, Karla; TRAVERSINI, Clarice; LOCKMANN, Kamila. A Educação em Tempos de Covid-19: ensino remoto e exaustão docente. Práxis Educativa, Ponta Grossa, v. 15, p. 1-24, ago. 2020.

SILVA, Maria da Graça Moreira da. De Navegadores a Autores: a construção do currículo no mundo digital. In: ENCONTRO NACIONAL DE DIDÁTICA E PRÁTICA DE ENSINO, 2010, Belo Horizonte. Anais... Belo Horizonte: Universidade Federal de Minas Gerais, 2010. 
Flávia Marcele Cipriani é Doutoranda em Educação pela Universidade Católica de Petrópolis. Mestra em Psicologia pela Universidade Federal de Juiz de Fora. Especialista em Gestão e Inspeção Escolar pelo Centro de Ensino Superior de Juiz de Fora (CES/JF). Graduada e licenciada nos cursos de Letras (CES/JF) e Pedagogia (CES-JF/PUC-MG).

ORCID: https://orcid.org/0000-0001-7242-8418

E-mail: flaviamcipriani@yahoo.com.br

Antônio Flávio Barbosa Moreira é Doutor em Educação pelo Instituto de Educação da Universidade de Londres (UCL). Realizou estágio Sênior PósDoutoral (UCL). Mestre em Educação pela Universidade Federal do Rio de Janeiro (UFRJ). Licenciado em Química (UFRJ). Graduado em Pedagogia pela Sociedade Universitária Augusto Motta. Graduado em Química Industrial pela Universidade do Brasil.

ORCID: https://orcid.org/0000-0001-7097-0238

E-mail: afmcju@gmail.com

Ana Carolina Carius é Doutora e Mestra em Modelagem Computacional pelo Laboratório Nacional de Computação Científica (LNCC). Graduada e licenciada em Matemática pela Universidade Federal do Rio de Janeiro (UFRJ).

ORCID: https://orcid.org/0000-0002-7284-665X

E-mail: carol.carius.oliveira@gmail.com

Editora-responsável: Fabiana de Amorim Marcello

Este é um artigo de acesso aberto distribuído sob os termos de uma Licença Creative Commons Atribuição 4.0 Internacional. Disponível em: <http:// creativecommons.org/licenses/by/4.0>. 